\title{
Severe hypersensitivity pneumonitis associated with everolimus therapy for neuroendocrine tumour: a case report
}

\author{
Camille Sibertin-Blanc ${ }^{1}$, Emmanuelle Norguet ${ }^{1}$, Muriel Duluc ${ }^{1}$, Guillaume Louis², Jean-François Seitz \\ and Laetitia Dahan ${ }^{1,3^{*}}$
}

\begin{abstract}
Background: Novel therapeutic agents are currently being investigated for neuroendocrine tumour treatment. Case presentation: We report here on the case of a patient presenting with hypersensitivity pneumonitis while being treated with everolimus, a mammalian target of rapamycin (mTOR) inhibitor.

Conclusion: Side effects of everolimus should be familiar to clinicians, including nonspecialists, and be monitored carefully to allow for prompt management.
\end{abstract}

Keywords: Neuroendocrine tumor, Everolimus, Hypersensitivity pneumonitis

\section{Background}

The incidence of neuroendocrine tumours is increasing. They are often diagnosed at an advanced stage, with conventional chemotherapy treatments having a limited effect. Therefore, novel therapeutic agents are currently being investigated, notably everolimus, a mammalian target of rapamycin (mTOR) inhibitor.

Neuroendocrine tumours have recently been shown to display a genetic anomaly that may lead to an activation of the mTOR pathway [1]. The mTOR kinase protein, however, is a central regulator of cellular proliferation, growth, angiogenesis, and metabolism [2]. The predominant side effects of everolimus therapy include mucositis and buccal ulcers, but less commonly, hypersensitivity pneumonitis. We report here on the case of a patient presenting with hypersensitivity pneumonitis while being treated with everolimus.

\section{Case presentation}

A 52-year-old man was followed up in our centre for a small intestinal neuroendocrine tumour with hepatic synchronous metastases diagnosed in 2001. The patient

\footnotetext{
* Correspondence: laetitia.dahan@mail.ap-hm.fr

${ }^{1}$ Assistance Publique - Hôpitaux de Marseille, Service d'oncologie digestive, Hôpital Timone, Université de la Méditerranée, Marseille, France

${ }^{3} \mathrm{CHU}$ Timone, 264 rue Saint Pierre, F-13385 Marseille cedex 5, France

Full list of author information is available at the end of the article
}

initially underwent small bowel and hepatic surgery combined with radiofrequency ablation, the latter being repeated in 2005 for a recurrence of hepatic metastases. Due to the progression of the disease, the patient was included in the Radiant-2 [3] trial that evaluated the efficacy of octreotide plus everolimus versus placebo plus octreotide on progression-free survival (PFS); he remained in the study for a period of 2 years. Following the initial stabilisation of the hepatic lesions, the patient experienced disease progression, leading to withdrawal from the study. Unblinding revealed that the patient was in the placebo plus octreotide arm.

In February 2010, everolimus therapy was initiated. Three months later, the first evaluation revealed a partial response, with a decrease in tumour size by $28 \%$ according to RECIST (Response Evaluation Criteria In Solid Tumours) criteria. During the 4th month of treatment, the patient experienced disabling dyspnoea of grade 2, without cough. Blood gas analysis showed uncompensated respiratory alkalosis. On thoracic computed-tomography (CT) scan, there was a pattern of alveolar condensation and air bronchogram in the left and right inferior lobes (Figure 1). Pulmonary function testing revealed a moderate restrictive syndrome. The bronchoalveolar lavage (BAL) showed lymphocyte-predominant alveolitis, while bacterial screening and serology tests of atypical pneumonia were 

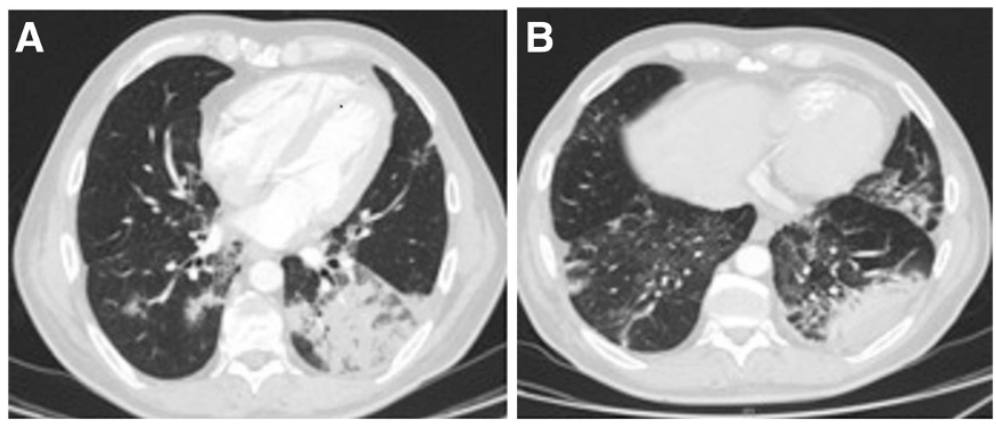

Figure 1 Scan taken at 4 months following the initiation of everolimus therapy during the dyspnoea episode: alveolar condensation of the right and left inferior lobe with an air bronchogram, predominant on the left-side.

negative. It was assumed that the patient's symptoms were due to Grade 3 hypersensitivity pneumonitis, which was likely linked to everolimus therapy. Consequently, the treatment was interrupted, following which the patient's respiratory symptoms returned to normal as did CT images (Figure 2).

\section{Discussion}

Everolimus is currently used in the treatment of a number of diseases: metastatic renal cancer resistant to sorafenib or sunitinib, non-small cell lung cancer unresponsive to anti-epidermal growth factor receptor (EGFR) therapy, as well as in cardiac or renal transplant patients. In addition, the drug is undergoing evaluation in metastatic breast cancer, gastric cancer, hepatocellular carcinoma, and nonHodgkin lymphoma.

Two phase III trials assessed the efficacy of everolimus on PFS. In the Radiant-3 trial [4] conducted on patients with pancreatic neuroendocrine tumours, everolimus was associated with a significant 6.4-month increase in median PFS versus placebo. Median PFS was 11 months with everolimus plus best supportive care, compared

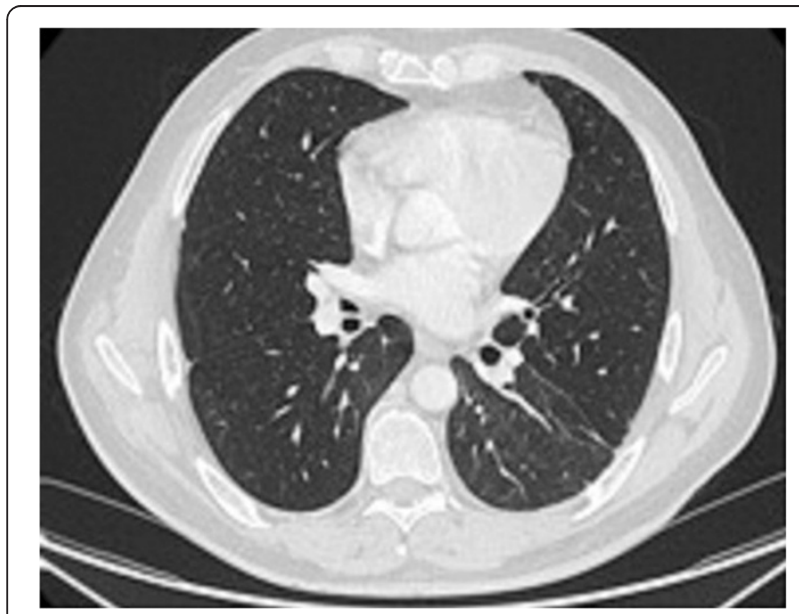

Figure 2 Control scan at 4 months after everolimus discontinuation: regression of bilateral parenchymatous lesions. with 4.6 months for placebo plus best supportive care (hazard ratio $=0.35$; 95\% Confidence Interval $(\mathrm{CI})[0.27$ $0.45])$. In the Radiant-2 trial [3], the improvement in PFS in patients with advanced neuroendocrine tumours just missed statistical significance at the predetermined level set by the study design, but median overall survival was higher in the everolimus arm compared with the placebo arm, 12 vs. 8.6 months (hazard ratio $=0.77, \mathrm{P}=$ 0.026), respectively.

As described in the literature [5], the most frequently reported side-effects of everolimus include infections, oedematous syndrome, cutaneous reactions (e.g., rash, itching, and dry skin), gastrointestinal problems (e.g., mucositis, diarrhoea, anorexia, nausea, and vomiting), asthenia, acute renal insufficiency, and pulmonary disease, including pneumonitis as in the case of our patient. Noninfectious pneumonitis is a known class effect of rapamycin derivatives. This side-effect was found in $13.5 \%$ [5] to $25 \%$ [6] of cases in the two major everolimus efficacy trials (12\% in the Radiant- 2 trial and $17 \%$ in Radiant- 3 ) and was more commonly Grade 1-2 (10-14\% being Grade 1-2 and $2-3 \%$ Grade $3-4)[3,4]$.

Symptoms of pneumonitis include dry cough, dyspnoea, hypoxemia, asthenia, fever, and weight loss [7,8], developing between 34 and 491 days after treatment initiation [5-8]. On radiographic and CT lung imaging, infiltration or opacity of the lower lobes may be observed $[6,9]$, even in the absence of pulmonary symptoms [5]. The BAL shows lymphocytic alveolitis, with samples testing negative for infection $[7,8]$. The development of this type of pneumonitis appears to be independent from serum everolimus levels [8]. The physiopathology of pneumonitis is likely based on the accumulation of collagen in the extracellular matrix, the proliferation and migration of fibroblasts, and the loss of functional alveolar gas exchange units [10].

Management depends on the severity of clinical symptoms, though the pneumonitis is usually reversible after dose reduction or treatment discontinuation $[5,6,8,11,12]$. In cases where the diagnosis is based on radiographic 
findings alone without any associated symptoms, everolimus may be continued at the same dose. In cases of moderate to severe symptoms, everolimus therapy should be temporarily stopped until pneumonitis has resolved, then re-instituted at a lower dose. Corticosteroids may also be administered [5].

\section{Conclusion}

These relatively frequent side effects of everolimus should be familiar to clinicians, including nonspecialists, and be monitored carefully to allow for prompt management. Recommendations for optimal management strategies are necessary.

\section{Consent}

Written informed consent was obtained from the patient for publication of this Case report and any accompanying images. A copy of the written consent is available for review by the Editor-in-Chief of this journal.

\section{Competing interest}

The authors declare that they have no competing interests.

\section{Authors' contributions}

Manuscript writing: L Dahan and C Sibertin-Blanc. Review: L Dahan, C Sibertin, JF Seitz. Final responsibility for the decision to submit for publication: $L$ Dahan. All authors read and approved the final manuscript.

\section{Acknowledgements}

This research did not receive any specific grant from any funding agency in the public, commercial or not-for-profit sector.

\section{Author details}

${ }^{1}$ Assistance Publique - Hôpitaux de Marseille, Service d'oncologie digestive, Hôpital Timone, Université de la Méditerranée, Marseille, France. ${ }^{2}$ Assistance Publique - Hôpitaux de Marseille, Service de radiologie, Hôpital Timone, Université de la Méditerranée, Marseille, France. ${ }^{3} \mathrm{CHU}$ Timone, 264 rue Saint Pierre, F-13385 Marseille cedex 5, France.

Received: 8 July 2013 Accepted: 8 November 2013

Published: 18 November 2013

\section{References}

1. Missiaglia E, Dalai I, Barbi S: Pancreatic endocrine tumors: expression profiling evidences a role for AKT-mTOR pathway. J Clin Oncol 2010, 28(2):245-255.

2. Faivre $\mathrm{S}$, Kroemer $\mathrm{G}$, Raymond E: Current development of mTOR inhibitors as anticancer agents. Nat Rev Drug Disc 2006, 5:671-688.

3. Pavel M, Hainsworth JD, Baudin E: A randomized double blind, placebocontrolled multicenter phase III trial of everolimus plus octreotide LAR vs placebo plus Octreotide LAR in patients with advanced neuroendocrine tumors (Radiant-2). Eur J Cancer 2010. LBA8.

4. Yao JC, Shah MH, Ito T: RAD001 In advanced neuroendocrine tumors, third trial (RADIANT-3) study group. Everolimus for advanced pancreatic neuroendocrine tumors. N Engl J Med. 2011, 364(6):514-523.

5. White DA, Camus P, Endo M: Noninfectious pneumonitis after everolimus therapy for advanced renal cell carcinoma. Am J Respir Crit Care Med 2010, 182(3):396-403.

6. White DA, Schwartz LH, Dimitrijevic S: Characterization of pneumonitis in patients with advanced non-small cell lung cancer treated with everolimus (RAD001). J Thorac Oncol 2009, 4(11):1357-1363.

7. Errasti $P$, Izquierdo D, Martín P: Pneumonitis associated with mammalian target of rapamycin inhibitors in renal transplant recipients: a single-center experience. Transplant Proc 2010, 42(8):3053-3054.
8. Rodríguez-Moreno A, Ridao N, García-Ledesma P: Sirolimus and everolimus induced pneumonitis in adult renal allograft recipients: experience in a center. Transplant Proc 2009, 41(6):2163-2165.

9. Otton J, Hayward CS, Keogh AM: Everolimus-associated pneumonitis in 3 heart transplant recipients. J Heart Lung Transplant 2009, 28(1):104-106.

10. Sánchez-Fructuoso Al, Ruiz JC, Pérez-Flores I: Comparative analysis of adverse events requiring suspension of mTOR inhibitors: everolimus versus sirolimus. Transplant Proc 2010, 42(8):3050-3052.

11. Alexandru S, Ortiz A, Baldovi S: Severe everolimus-associated pneumonitis in a renal transplant recipient. Nephrol Dial Transplant 2008, 23(10):3353-3355.

12. Expósito V, de Prada JA, Gómez-Román JJ: Everolimus-related pulmonary toxicity in heart transplant recipients. J Heart Lung Transplant 2008, 27(7):797-800

doi:10.1186/1756-0500-6-471

Cite this article as: Sibertin-Blanc et al.: Severe hypersensitivity pneumonitis associated with everolimus therapy for neuroendocrine tumour: a case report. BMC Research Notes 2013 6:471.

\section{Submit your next manuscript to BioMed Central and take full advantage of:}

- Convenient online submission

- Thorough peer review

- No space constraints or color figure charges

- Immediate publication on acceptance

- Inclusion in PubMed, CAS, Scopus and Google Scholar

- Research which is freely available for redistribution 